\title{
Experimental investigation on hard turning using mixed ceramic insert under accelerated cooling environment
}

\author{
Ramanuj Kumar, Ashok Kumar Sahoo*, Purna Chandra Mishra, Rabin Kumar Das and Manoj \\ Ukamanal
}

School of Mechanical Engineering, KIIT University, Bhubaneswar-24, Odisha, India

\begin{tabular}{l}
\hline C H R O N I C L E \\
\hline Article history: \\
Received August 182017 \\
Received in Revised Format \\
August 252017 \\
Accepted November 92017 \\
Available online \\
November 92017 \\
\hline Keywords: \\
Accelerated cooling environment \\
Machinability \\
Tool life \\
Grey relational analysis \\
Empirical model
\end{tabular}

\section{Introduction}

In recent years, hard turning of heat treated steel are widely acceptable and successfully replaced the costly cylindrical grinding process. CBN, PCBN, ceramic and cermet tools are more popular for hard turning operations under dry condition (Chinchanikar \& Choudhury, 2015). Some unfavorable tribological phenomena of dry cutting such as higher friction causes faster tool wear and surface roughness leading to improper shape and dimensional accuracy (Grzesik, 2009). Today, in hard turning the prime objective of researchers are to reduce machining cost and improves the productivity by reducing the tool wear rate. Because of this, focus on application of environmental conscious lubricating system in hard turning is emerging. Some techniques like minimum quantity lubrication (MQL), high pressure cutting fluid application, and spray impingement cooling are emerging as improved cutting fluid techniques compared to flooded cooling and dry surroundings which were reported by various researchers (Chinchanikar \& Choudhury, 2015; Sharma et al., 2014; Sahu et al., 2015; Mishra et al., 2015).

* Corresponding author

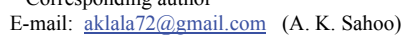

2018 Growing Science Ltd.

doi: $10.5267 /$ j.ijiec.2017.11.002

\begin{abstract}
The present study reports on the application of accelerated cooling environment (ACE) in hard turning of AISI D2 steel $(55 \pm 1 \mathrm{HRC})$ using mixed ceramic insert $\left(\mathrm{Al}_{2} \mathrm{O}_{3}+\mathrm{TiCN}\right)$ which is rarely being investigated and to address the major problems of brittle fracture of tool tip that arises through cutting forces and friction at tool-work and chip-tool interface. In spraying process, some remaining portion of coolant easily penetrate in cutting zone through capillary action and reduces friction as well as heat in cutting zone. Abrasion and chipping are noticed to be dominant wear mechanism. Cutting speed and depth of cut are significant for flank wear as well as cutting temperature whereas feed is significant for average surface roughness. Serrated chips have been identified at higher cutting speed and higher feeds. Optimal parametric combination is found to be d1-f1-v2 $(0.1 \mathrm{~mm}-0.04 \mathrm{~m} / \mathrm{min}-108 \mathrm{~m} / \mathrm{min})$ and tool life and machining cost per part are 70 minutes and Rs 76.76 respectively. Investigation shows the worthy of application of ACE in hard turning in industrial sectors ecologically and economically. Empirical models reveal statistically significance due to higher coefficient of correlations.
\end{abstract}


Absence of lubricant/coolant in high speed turning of heat treated steel created the chip disposal problem which increases the amount of friction at tool-chip and tool-work contact thus leading in accelerated attrition as well as tool wear. However abundant amount of coolant was advantageous for reducing frictions but simultaneously increases the machining cost and produced some undesirable health issues for the human being. However MQL and compressed air-water spray plays a compromising lubrication technique between flooded and dry cutting (Chinchanikar \& Choudhury, 2015). Sharma et al. (2014) found that the machining of heat-treated D2 steel under MQL condition compiles better results of dry surroundings in terms of cutting temperature and surface quality. Sahu et al. (2015) implemented compressed air-water mixing spray in hard turning of heat treated AISI 1015 steel and found reduced temperature as well as surface roughness compared to dry. The optimal spray parameters were found to be 1.5 bar air pressure and 1 bar water pressure. Mishra et al. (2014) also used spray technique and observed better result compared to dry. ANOVA result showed that the cutting feed was the most dominating term for all output characteristics in both cutting surroundings. Mia and Dhar (2016) researched on the study of surface quality in finish turning of heat-treated steel using carbide insert in dry and high pressure cooling surroundings. High pressure coolant developed effective cooling and lubrication with reduced amount of friction thus improved surface quality compared to dry surroundings produced.

In the past years, many works have been carried using ceramic inserts under dry condition. Grzesik (2009) noticed that the alumina based ceramic insert performed well due to its high hot hardness capacity up to $1500^{\circ} \mathrm{C}$, excellent abrasive resistance and chemical stability. The wear on flank surface was observed as grooves due to abrasive and adhesion mechanism. According to Aslantas et al. (2012) crater wear was noticed to be most dominating wear because of chipping or tool tips cracking within short a period of time. Machining with uncoated ceramic tool produced higher temperature than coated ceramic tool due to lower conductivity of the uncoated tool. Davim and Figueira (2007) examined the machinability of heat treated D2 steel with application of ceramic tool and noticed that the tool wear was highly sensitive and it was increasing with cutting velocity and cutting time. The surface quality was highly affected by feed rate and cutting time. According to Mondal et al. (2011) depth of cut was noticed to be a highly influencing factor for flank wear succeeded by cutting speed and cutting feed. Makadia and Nanavati (2013) established the RSM based equations and noticed that the feed was the main influencing term regarding average surface roughness succeeded by tool tip radius. Surface quality seemed to be deteriorating with rise in feed and improved with rise in tool tip radius. Das et al. (2015) presented a detailed investigation on response like flank wear, average surface roughness and chip morphology on turning of heat treated AISI 4140 steel with use of ceramic inserts under dry surrounding. Cutting feed was the most compelling factor towards surface roughness whereas depth of cut did not affect considerably. Higher contribution of speed was noticed on flank wear succeeded by cutting feeddepth of cut interaction and cutting feed. Saw tooth pattern chips were noticed due to periodic propagation of cracks. Gaitonde et al. (2009) noticed lower magnitudes of surface roughness at smaller magnitudes of depth of cut whereas up to depth of cut $0.4 \mathrm{~mm}$ wear decreased with rise in depth of cut. Özel et al. (2007) found the flank wear of $0.15 \mathrm{~mm}$ in hard cutting of D2 steel within 15 minutes whereas improved surface quality was noticed at lowest cutting feed along with maximum cutting speed condition. Sahin (2009) noticed that the cutting speed largely affected the tool wear succeeded by hardness of inserts and cutting feed whereas for tool life concern feed was highly significant. De Godoy and Diniz (2011) mentioned that the abrasion was major wear mechanism for ceramic tool while for CBN tool the abrasion mechanism at lowest cutting speed and diffusion mechanism at highest cutting speed were noticed. Grzesik and Zalisz (2008) emphasized on wear mechanism of ceramic steel during turning tests. The various mechanisms like abrasion, adhesion, fracture, plastic deformation, diffusion of materials were noticed. Grzesik (2008) experimentally found that in finish hard machining wear was identified on flank faces of tool as well as on trailing edge of tool. For both tools (wiper and conventional ceramic) at constant feed $0.1 \mathrm{~mm} / \mathrm{rev}$ surface roughness was increasing subsequently with rise in cutting time. Basak et al. (2007) concluded that to achieve 0.8 micron surface roughness the cutting speed must be $220 \mathrm{~m} / \mathrm{min}$ whereas for maximum productivity the feed must lies from 0.11 to $0.15 \mathrm{~mm} / \mathrm{rev}$. Ferreira et al. (2014) 
found that the multi-radii cutting tool produced better quality of finished surface compare to convention ceramic tool. With rise in feed surface quality got deteriorate relatively for both tools. Quiza et al. (2008) performed a machining analysis on D2 steel with use of ceramic insert. ANN model produced more closed model compare to regression. Yallese et al. (2004) found the rapid tool wear thus catastrophic damage of ceramic tool tip at machining with $120 \mathrm{~m} / \mathrm{min}$ speed whereas at speed $180 \mathrm{~m} / \mathrm{min}$ the tool tip got totally collapse. Shalaby et al. (2014) noticed that the ceramic tool had higher tool life along with lower turning forces compare to PCBN tool. PCBN tool may get damage due to abrasion, diffusion and adhesion mechanism.

From the literature studied, it can be stated that the ceramic inserts in hard turning applications under dry surroundings are widely accepted. Ceramic material is highly sensitive to brittle fracture due to thermal shocks if coolant is used during machining. Hence, there should be an intermediate medium between dry and wet surroundings that leads to improve the heat transfer as well as reduction of friction and called accelerated cooling environment (ACE). This may improve the hard machining performance of ceramic insert compared to dry machining. In this work, spray impingement cooling technique called ACE has been employed in hard turning of D2 steel using ceramic insert like minimum quantity lubrication and investigates the machinability aspects. Empirical modeling, parametric optimization, tool life and cost aspects have also been studied in details for its feasibility in industrial applications which present itself the novelty of present investigations.

\section{Machining details}

Heat treated D2 steels are widely used in automotive industries, moulds and dies making industries etc. Hence in the present work, D2 steel $(55 \pm 1 \mathrm{HRC})$ of $\Phi 48 \mathrm{~mm} \times 220 \mathrm{~mm}$ has been chosen as testspecimen to investigate their machinability under $\mathrm{ACE}$ environment. WIDIA made ceramic Insert $\left(\mathrm{Al}_{2} \mathrm{O}_{3}\right.$ + TiCN) of geometry CNMG 120408 mounted with right hand negative rake tool holderPCLNR2525M12 are used for machining. Cutting parameters with their levels selected for experiment are cutting speed $(63,108,140$ and $182 \mathrm{~m} / \mathrm{min})$, feed $(0.04,0.08,0.12$ and $0.16 \mathrm{~mm} / \mathrm{rev})$ and depth of cut $(0.1,0.2,0.3$ and $0.4 \mathrm{~mm})$. Taguchi $\mathrm{L}_{16}$ (Panda et al., 2016; Rout et al., 2012)) set of experiments have been chosen to conduct the turning experiments on HMT lathe (NH 22) of $11 \mathrm{~kW}$ power capacity with spindle speed ranges from 40 to $2040 \mathrm{rpm}$. The responses like flank wear, average surface roughness, cutting temperature at chip-tool interface, chip morphology and chip reduction coefficient have been investigated. The images of wear width and chip have been capture through inbuilt SC30 camera in Olympus STM 6 optical microscope. Surface roughness is measured at different five location of turned surface and its average value is considered using surface roughness tester, Taylor Hobson (Sutronic 25).

Table 1

Test results

\begin{tabular}{|c|c|c|c|c|c|c|c|c|c|}
\hline Run & $\begin{array}{c}\mathrm{d} \\
(\mathrm{mm})\end{array}$ & $\begin{array}{c}\mathrm{f} \\
(\mathrm{mm} / \mathrm{rev})\end{array}$ & $\begin{array}{c}\mathrm{v} \\
(\mathrm{m} / \mathrm{min})\end{array}$ & $\begin{array}{c}\mathrm{Ra} \\
(\mu \mathrm{m})\end{array}$ & $\begin{array}{c}\mathrm{T} \\
\left({ }^{0} \mathrm{C}\right)\end{array}$ & $\begin{array}{c}\mathrm{VBc} \\
(\mathrm{mm})\end{array}$ & Chip Shape & $\begin{array}{l}\text { Chip } \\
\text { Colour }\end{array}$ & $\mathrm{CRC}$ \\
\hline 1 & 0.1 & 0.04 & 63 & 0.514 & 101 & 0.012 & Helical \& Saw tooth & Metallic & 1.455 \\
\hline 2 & 0.1 & 0.08 & 108 & 0.592 & 107 & 0.018 & Helical \& Saw tooth & Metallic & 1.380 \\
\hline 3 & 0.1 & 0.12 & 140 & 0.74 & 119.1 & 0.034 & Spiral c type \& Saw tooth & Blue & 1.338 \\
\hline 4 & 0.1 & 0.16 & 182 & 1.114 & 163.4 & 0.058 & Spiral c type \& Saw tooth & Burnt blue & 1.254 \\
\hline 5 & 0.2 & 0.04 & 108 & 0.432 & 120.3 & 0.028 & Helical \& Saw tooth & Metallic & 1.556 \\
\hline 6 & 0.2 & 0.08 & 63 & 0.548 & 133.3 & 0.024 & Spiral c \& $\varepsilon$ type $\&$ Saw tooth & Metallic & 1.757 \\
\hline 7 & 0.2 & 0.12 & 182 & 0.868 & 177.5 & 0.048 & Ribbon \& Saw tooth & Blue & 1.589 \\
\hline 8 & 0.2 & 0.16 & 140 & 1.066 & 139.5 & 0.04 & Ribbon \& Saw tooth & Blue & 1.380 \\
\hline 9 & 0.3 & 0.04 & 140 & 0.472 & 151.8 & 0.048 & Helical \& Saw tooth & Partial blue & 1.656 \\
\hline 10 & 0.3 & 0.08 & 182 & 0.678 & 182 & 0.058 & Ribbon \& Saw tooth & Partial blue & 1.631 \\
\hline 11 & 0.3 & 0.12 & 63 & 0.93 & 143.5 & 0.039 & Helical \& Saw tooth & Partial blue & 1.840 \\
\hline 12 & 0.3 & 0.16 & 108 & 1.107 & 135.6 & 0.034 & Spiral c \& $\varepsilon$ type $\&$ Saw tooth & Partial blue & 1.568 \\
\hline 13 & 0.4 & 0.04 & 182 & 0.592 & 180.9 & 0.079 & Spiral c type \& Saw tooth & Metallic & 1.606 \\
\hline 14 & 0.4 & 0.08 & 140 & 0.64 & 167.9 & 0.05 & Helical \& Saw tooth & Metallic & 1.882 \\
\hline 15 & 0.4 & 0.12 & 108 & 0.806 & 161 & 0.032 & Ribbon \& Saw tooth & Blue & 1.840 \\
\hline 16 & 0.4 & 0.16 & 63 & 1.255 & 154.3 & 0.039 & Helical \& Saw tooth & Blue & 1.694 \\
\hline
\end{tabular}


Cutting temperature value and its images have been captured through Fluke Ti32 infrared camera. Chip thickness measured by digital caliper. Spraying system made by Spraying Systems India Pvt. Ltd. (India) is used for accelerated cooling taking air pressure 1.5 bar and water pressure 1 bar (fixed). Controlled pressure of air and water is mixed through internal blast nozzle of size 1/4 J. The experimental setup and results are shown in Table 1 and Fig. 1, respectively.

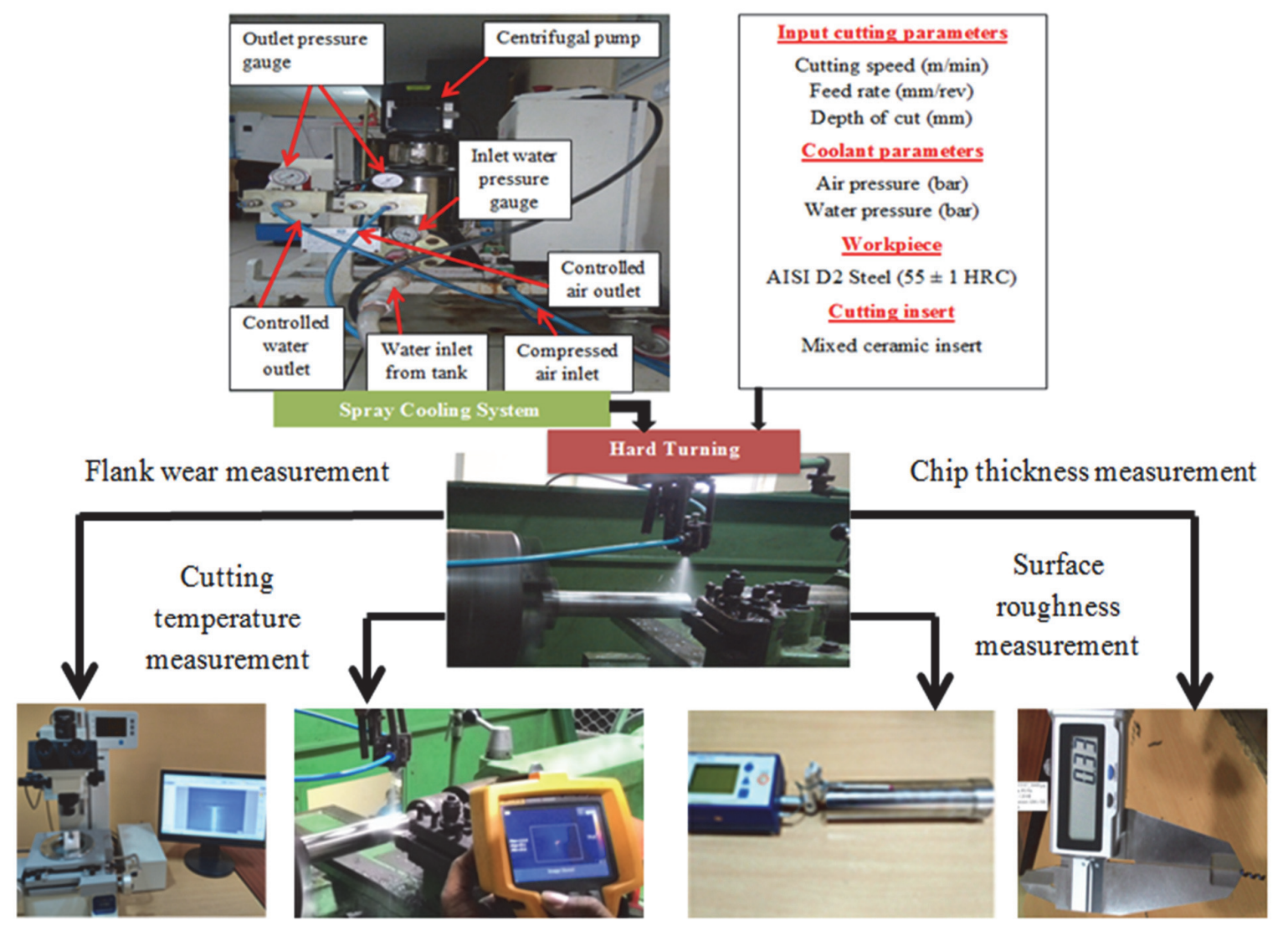

Fig. 1. Schematic overview of experimental investigation.

\section{Empirical Modeling}

Second order polynomial regression methodology has been implemented for empirical modeling (Chinchanikar \& Choudhury, 2015; Mir et al., 2018; Gupta, 2010). Modeling has been performed with uncoded units on $95 \%$ of level of confidence. The statistically implication and competency of empirical model has been validated using an analysis of variance (ANOVA) based on the calculated $f$ and $p$ values. In ANOVA implementation, the sum of squares is evaluated to assess the square of deviation from the noble mean (Süleyman et al., 2011; Sahoo \& Sahoo, 2013). If p value of developed model is under than 0.05 , significance of respective term has been established and the model has a significant influence on the considered output response (Sahoo et al., 2008). In empirical function, the term R-sq expressed the variation of fitted data from actual data whereas R-Sq (adj) value is needful when the model is being compared and checked with a different data set. When R-sq value approaches to unity (100\%), the desired output response model is fitted closely and effectively with the actual experimental result data.

The developed models for responses say flank wear (VBc), cutting temperature (T), average surface roughness (Ra) and chip reduction coefficient (CRC) are presented in Eqs. (1-4).

$$
\begin{aligned}
& \mathrm{VBc}=-0.00222+0.20793 d+0.26039 f-0.00033 v+0.01875 d^{2}+1.36719 f^{2}-1.41042 d f- \\
& 0.00024 d v-0.00156 f v \quad \mathrm{R}^{2}=99.15 \% \quad \mathrm{R}^{2}(\mathrm{pred})=92.66 \% \quad \mathrm{R}^{2}(\operatorname{adj})=97.87 \%
\end{aligned}
$$


$\mathrm{T}=103.42+410.19 d+70.37 f-0.97 v-180.62 d^{2}-1738.28 f^{2}+0.01 v^{2}-234.32 d f-0.96 d v+$

$2.70 f v \quad \mathrm{R}^{2}=99.32 \% \quad \mathrm{R}^{2}$ (pred) $=94.61 \% \quad \mathrm{R}^{2}(\operatorname{adj})=98.30 \%$

$$
\begin{aligned}
& \begin{array}{l}
\mathrm{Ra}=0.7129-0.6287 d-0.2101 f-0.0045 v+0.9500 d^{2}+29.2969 f^{2}+3.8404 d f-0.0005 d v- \\
0.0110 f v \quad \mathrm{R}^{2}=98.83 \% \quad \mathrm{R}^{2}(\text { pred })=91.44 \% \quad \mathrm{R}^{2}(\mathrm{adj})=97.07 \%
\end{array} \\
& \begin{array}{l}
\mathrm{CRC}=1.2279+4.4107 d+4.0528 f-0.0055 v-3.3000 d^{2}-42.5000 f^{2}-3.2865 d f-0.0055 d v+ \\
0.0329 f v \quad \mathrm{R}^{2}=99.00 \% \quad \mathrm{R}^{2}(\text { pred })=94.10 \% \quad \mathrm{R}^{2}(\mathrm{adj})=97.51 \%
\end{array}
\end{aligned}
$$

The developed empirical models (Eqs. 1-4) have larger magnitude of determination coefficients $\left(\mathrm{R}^{2}\right)$ presenting significance of model as it approaches to unity $(100 \%)$. For each model, the $\mathrm{R}^{2}$, Pred $\mathrm{R}^{2}$ and adj $\mathrm{R}^{2}$ values are also very near to each other. Model ANOVA (only presented for VBc) shows in Table 2 indicates statistically significance because of P-value lies below 0.05 with $95 \%$ confidence level. However it shows the goodness of fitting of the developed empirical models and can be safely and efficiently implemented in hard turning applications.

\section{Table 2}

ANOVA for VBc Model

\begin{tabular}{lccccccc}
\hline Source & DF & Seq SS & Adj SS & Adj MS & F & P & Remarks \\
\hline Regression & 9 & 0.004167 & 0.004167 & 0.000463 & 77.72 & 0.000 & Significant \\
Linear & 3 & 0.003358 & 0.003358 & 0.000077 & 12.96 & 0.005 & Significant \\
Square & 3 & 0.000448 & 0.000429 & 0.000143 & 23.98 & 0.001 & Significant \\
Interaction & 3 & 0.000361 & 0.000361 & 0.000120 & 20.18 & 0.002 & Significant \\
Residual error & 6 & 0.000036 & 0.000036 & 0.000006 & & & \\
\hline Total & 15 & 0.004203 & & & & \\
\hline
\end{tabular}

\section{Results morphology}

\subsection{Flank wear morphology}

In finish hard turning of D2 steel, tool wear is an important aspect for machinability of the cutting insert. From the detailed literature study, tool wear was classified into different types such as crater wear, flank wear, catastrophic failure, nose wear, notch wear, chipping and plastic deformation (Chinchanikar \& Choudhury, 2015). Higher temperature generation at the tool-workpiece interface is one of the basic factors behind the tool failure in finish hard turning. Flank wear seems to be the principal wear and identified that in each run, the magnitude of flank wear lies within the recommended range of $0.3 \mathrm{~mm}$ (Yallese et al., 2004; Sahoo \& Sahoo, 2013) and even below $0.1 \mathrm{~mm}$. This may be attributed due to the reduction of friction and thus cutting temperature at tool-chip contact by applying air-water mixed accelerating spray coolant. Abrasion is main tool wear mechanism noticed due to abrasive behavior of some hard elements associated with D2 steel and it agrees with the findings of (Pavel et al., 2005; Das et al., 2015). Chipping has been noticed at highest cutting speed and depth of cut with lowest feed as displayed in Fig. 2e and it agrees the result obtained by Yallese et al. 2004 as they found that machining at speed of $180 \mathrm{~m} / \mathrm{min}$ using ceramic tool produces micro chipping due to combine effect of diffusion at chemical action between tool and workpiece. Aslantas et al. (2009) also noticed chipping type of tool corner damage due to tool vibration and shock load during cutting. From the result Table 1, it can be traced that at minimal depth of cut $(0.1 \mathrm{~mm})$ the flank wear improves with rise in cutting speed and cutting feed values (Fig. 2a-d), whereas at highest depth of cut $(0.4 \mathrm{~mm})$ the wear width on flank surface decreases with rise in speed and feed (Fig. 2e-h). Maximum rate of wear in entire test runs is noticed with highest cutting speed $(182 \mathrm{~m} / \mathrm{min})$. However ceramic insert can be successfully employed in finishing hard turning operation of D2 steel under considered accelerated cooling environment.

The main effects plot (Fig. 3a) analysis revealed that the flank wear improves with the cutting speed as well as depth of cut whereas its remains almost stable with rise in feed showing less significant effect on flank wear which is well agreement with Das et al. (2015). ANOVA (similar to Table 2) result shows 
that cutting speed is the highest significant parameter for flank wear succeeded by depth of cut whereas feed is traced to be insignificant.

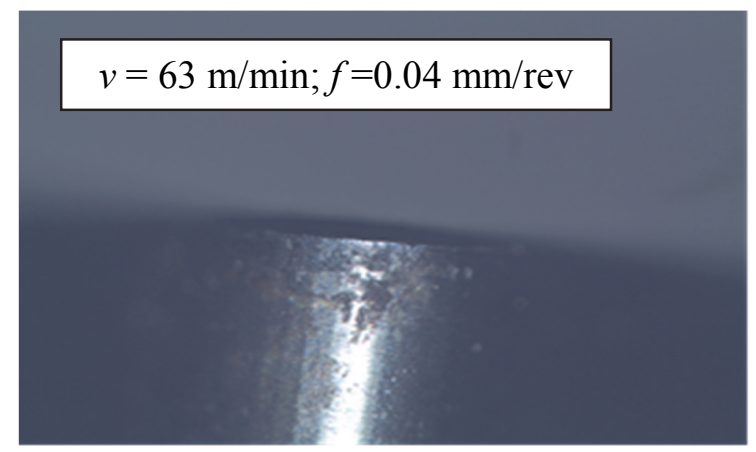

(a)

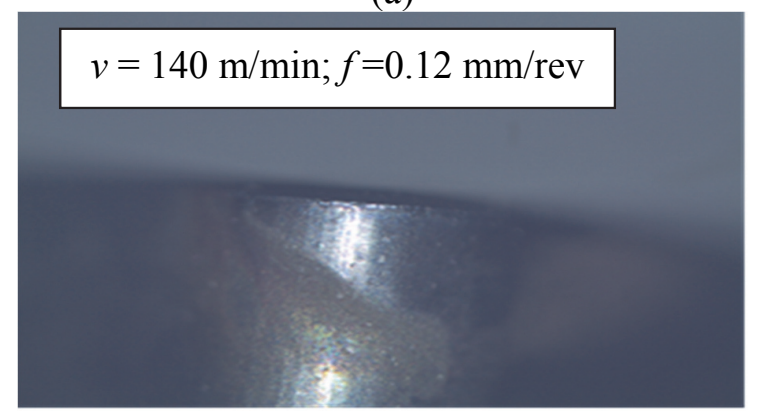

(c)

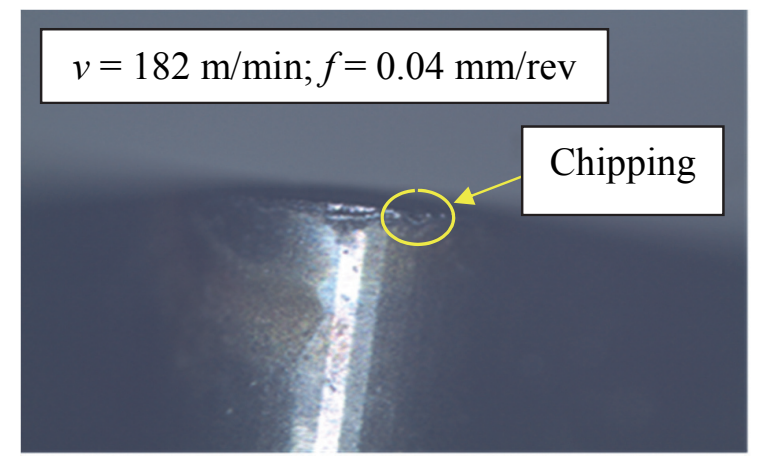

(e)

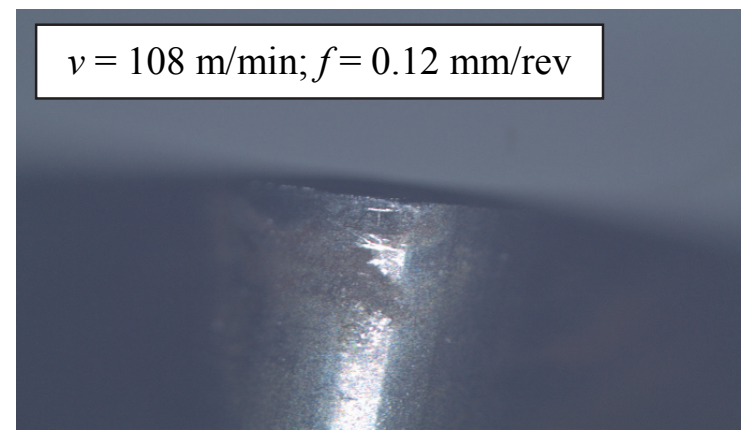

(g)

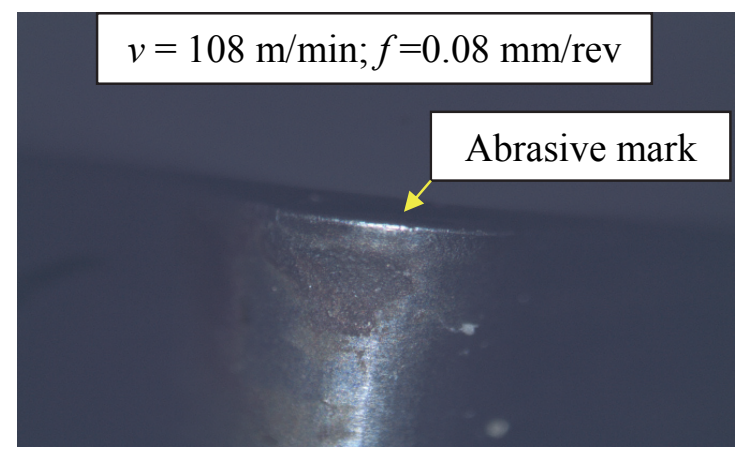

(b)

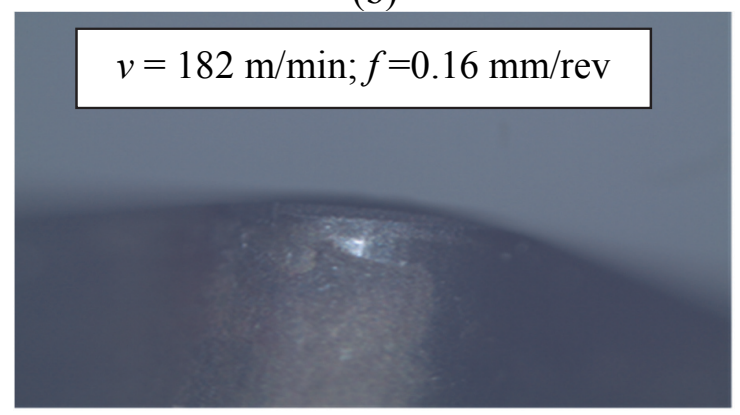

(d)

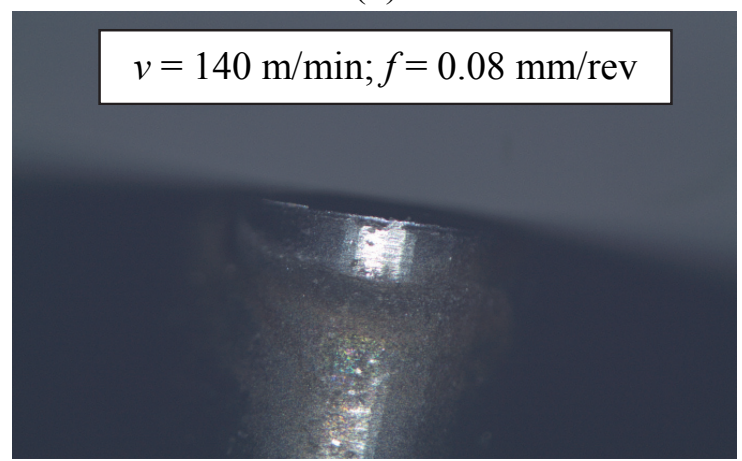

(f)

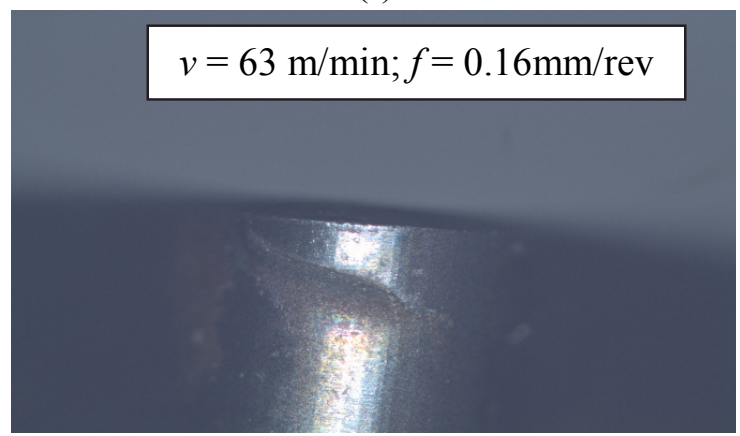

(h)

Fig. 2. (a-d) Flank wear images at depth of cut $0.1 \mathrm{~mm}(\mathrm{e}-\mathrm{h})$ Flank wear images at depth of cut $0.4 \mathrm{~mm}$ 


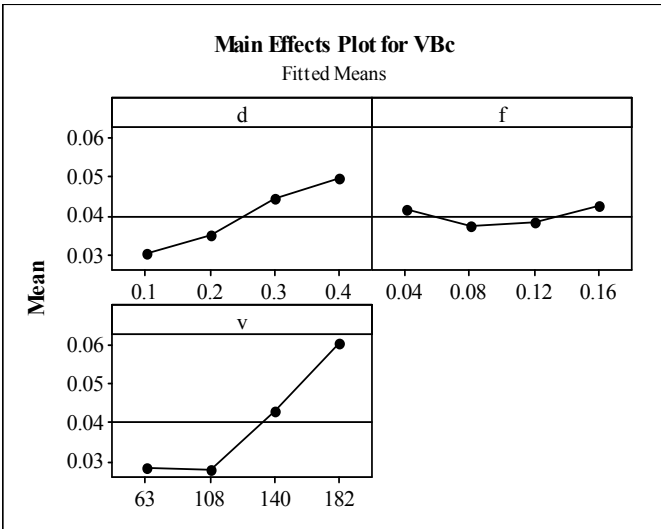

(a)

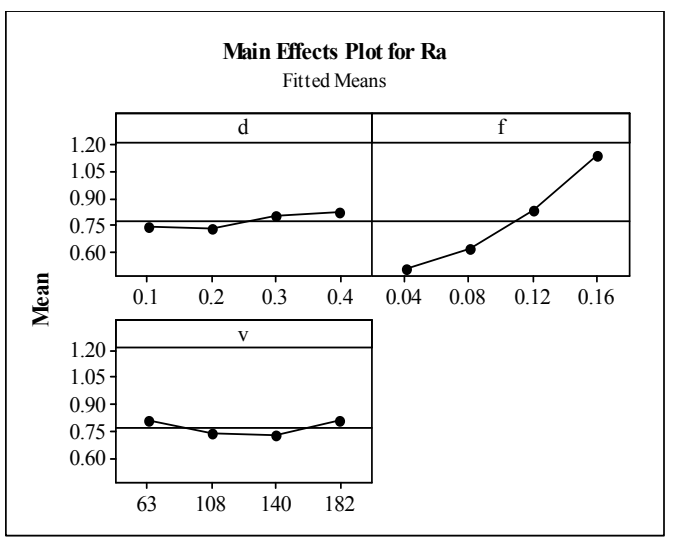

(b)

Fig. 3. Main effects plot for (a) Flank wear, VBc (b) Surface roughness, Ra

\subsection{Surface roughness morphology}

Good surface quality is highly demanded without sacrificing the productivity and thus very essential to analyze surface roughness $(\mathrm{Ra})$ of work material after machining. It will also be interesting to observe the surface quality in accelerated cooling condition. The measured average surface roughness values (Table 1) have been lie within the recommended limit range of 1.6 microns (Sahoo \& Sahoo, 2013). In fact up to $0.08 \mathrm{~mm} / \mathrm{rev}$ feed with entire range of considered speed and depth of cut, the surface roughness has been found below than 0.7 micron which is better than the surface roughness $(0.8$ micron $)$ produced by cylindrical grinder. At smallest depth of cut $0.1 \mathrm{~mm}$ with up to $0.12 \mathrm{~mm} / \mathrm{rev}$ feed, the roughness value seemed to be below than 0.8 micron. The poor quality of surface has been evolved with higher feed rates $(0.12 \mathrm{~mm} / \mathrm{rev}$ and $0.16 \mathrm{~mm} / \mathrm{rev})$. However it can be concluded that ceramic insert can perform extremely well under accelerated cooling condition with considered input parameters. Mean plot clearly report that the surface roughness improves with rise in feed whereas the effects of speed and depth of cut are not considerable as it varies along mean line. Davim and Figueira (2007) also noticed the improvement of surface roughness with rise in feed whereas reduces with rise in cutting speed. Makadia and Nanavati (2013) revealed that there is not considerable effect of depth of cut on surface roughness. From ANOVA result (similar as Table 2) and main effect plot (Fig. 3b), only feed is identified as significant term whereas speed as well as depth of cut is not statically important.

\subsection{Cutting temperature morphology}

In dry machining, high amount of heat generation in cutting zone is a major problem of failure of tool tip due to accelerated growth of tool wear and consequently retards the quality of machined surface. However for minimizing the wear rate and improving the quality of machined surface, hazard free lubrication is needed. In the present work, elevated pressure of air-water mix accelerated cooling system has been implemented and its effect on cutting temperature is analyzed. The temperature evolved during cutting reduces significantly as temperature found in between $101{ }^{\circ} \mathrm{C}$ (Fig. $4 \mathrm{a}$ ) to $182^{\circ} \mathrm{C}$ (Table 1). In spraying process, some portion of spraying coolant vaporize due to heat when it reaches to cutting zone whereas remaining portion of coolant easily penetrate in cutting zone through capillary action and reduces the friction as well as heat in cutting zone. Liu et al. (2005) and Sahu et al. (2015) also found that the cutting fluid entered in to cutting zone through capillary action and formed a very fine lubrication film which reduces the friction at chip-tool interface. In majority of runs, the chip-tool interface temperature increases with rise in cutting speed. Higher cutting speed leads to improve the frictional and shear energy which causes to rises the cutting temperature at tool-chip junction. Similar finding has been reported by (Pal et al., 2014). On smallest depth of cut $0.1 \mathrm{~mm}$, the temperature increases with rise in feed and cutting speed (Fig. 4a-d) whereas at highest depth of cut $0.4 \mathrm{~mm}$ the temperature drops with increase in feed and decrease in cutting speed (Table 1). This is probably happens due rise in feed and 
depth of cut which widen the cross-sectional area of chip however leads to better heat transformation in to the air-water mix spray coolant. Similar mechanism reported by (Pal et al., 2014). Chinchanikar and Choudhury (2015) identified that the chip-tool interface cutting temperature was greatly influenced by cutting speed succeeded by feed whereas depth of cut was not play a significant effect on cutting temperature. Main effects plot study revealed that the temperature reduces when cutting speed rises from $63 \mathrm{~m} / \mathrm{min}$ to $108 \mathrm{~m} / \mathrm{min}$ thereafter it improves with rise in cutting speed whereas it increases with increasing depth of cut. There is not any significant change in cutting temperature has been observed when feed rises. From ANOVA (Mandal et al., 2011) study (similar as Table 2) and main effect plot (Fig. 5a), cutting speed and depth cut are significant. Similar results reported by (Sahu et al., 2015) in their work. Out of these cutting variables, cutting speed acts as a more significant term succeeded by depth of cut whereas cutting feed is insignificant term for cutting temperature.

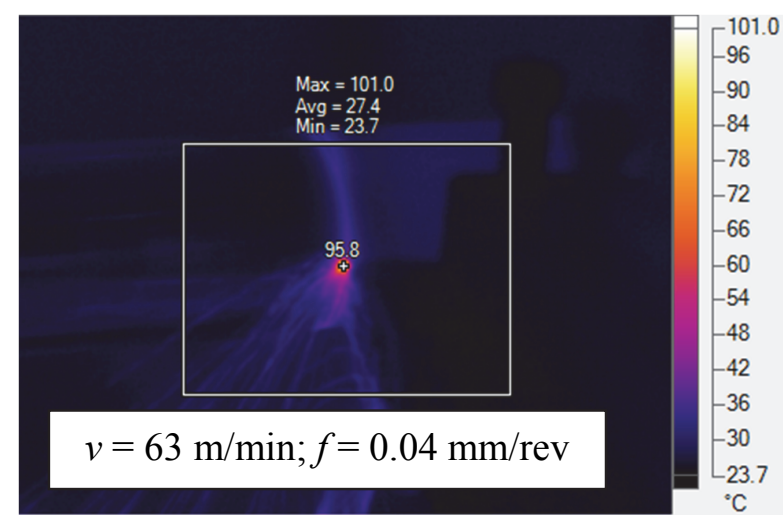

(a)

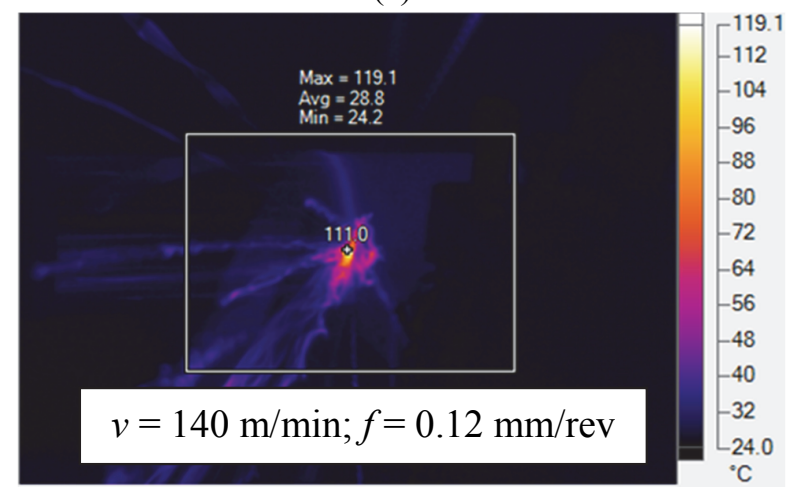

(c)

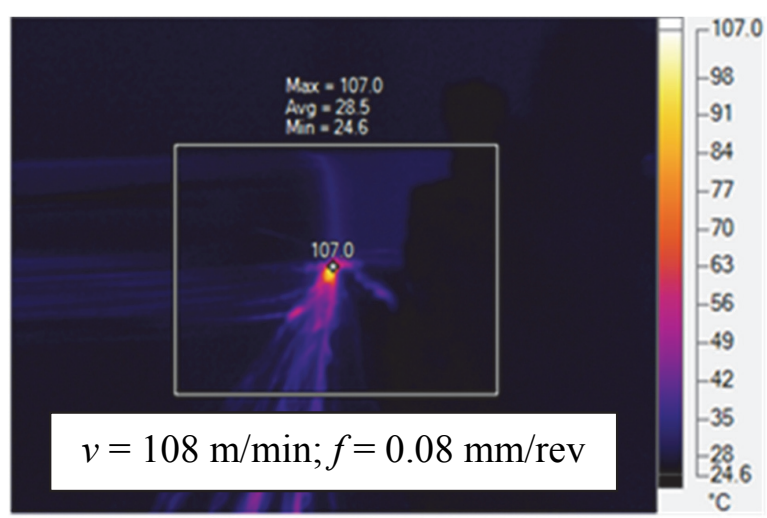

(b)

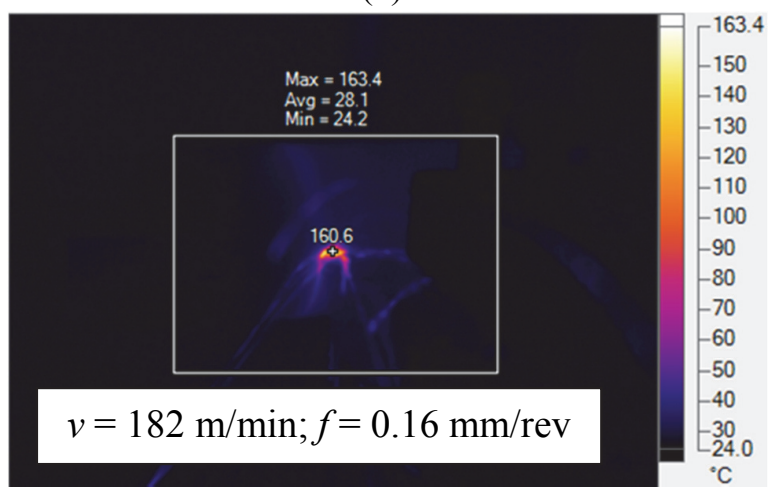

(d)

Fig. 4. Cutting temperature images at fixed depth of cut $0.1 \mathrm{~mm}$

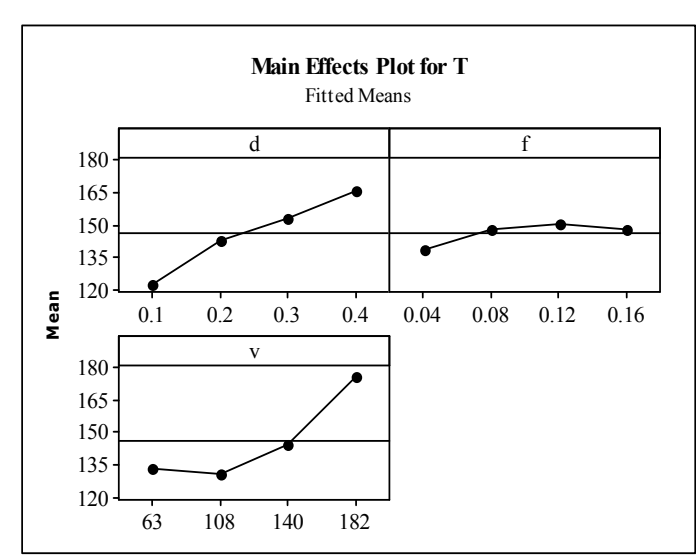

(a)

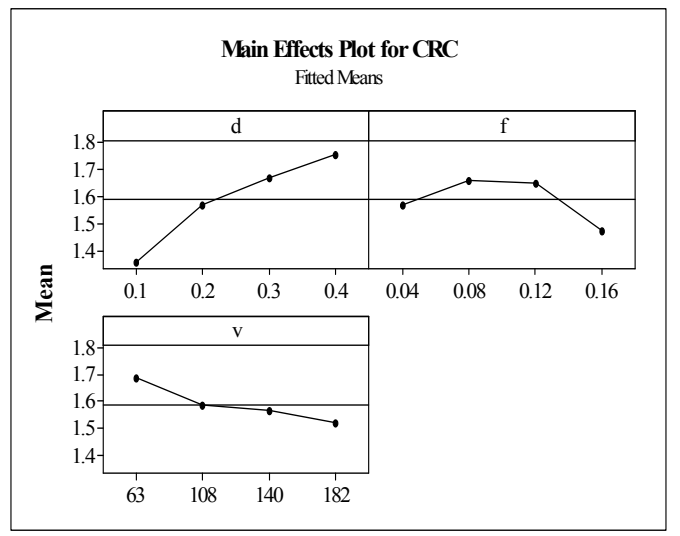

(b)

Fig. 5. Main effects plot for (a) Cutting temperature, $T$ (b) Chip reduction coefficient, CRC. 
The chip shape and colour of each experimental run has been listed in Table 1. Helical, spiral c type, spiral $\mathrm{c}$ and $\varepsilon$ type and ribbon shape of chips have been produced and presented through optical images in Fig. 6. Sahoo and Sahoo (2012) also reported similar chip shapes in hard turning. Metallic colour of chips have been noticed in all runs where smaller feed rate conditions $(0.04$ and $0.08 \mathrm{~mm} / \mathrm{rev})$ are applied except at depth of cut $0.3 \mathrm{~mm}$. Burnt blue colour (Fig. 6d) of chip produced at highest cutting speed and cutting feed cutting condition. With depth of cut $0.3 \mathrm{~mm}$ only partial blue colour chips produced whereas blue chips are noticed at higher feed values $(0.12 \mathrm{~mm} / \mathrm{rev}$ and $0.16 \mathrm{~mm} / \mathrm{rev})$ except depth of cut $0.3 \mathrm{~mm}$ and run 4 . Blue and burnt blue colour chips indirectly indicate the sufficient amount of heat is carried by chips that mean very low amount of heat goes to workpiece. Saw tooth chip is noticed in every run. Saw tooth chip (Fig. 6a-j) developed because of periodic fracture by generating very high concentrating shear bands and it agrees with result reported by Das et al. 2015. Fig. 6j presented the top and bottom surface of the chip at run 7. Top face of chip is plastically deformed and looking dull whereas the bottom surface of chip is looking smooth and shine because of continuous rubbing between tool and chip surface. Serrated chips (Fig. 6j) have been identified at higher cutting speed and/or higher feed ranges similarly by Das et al. (2015).

Chip reduction coefficient (CRC) is directly proportional to chip thickness and it denotes the intensity of cutting forces and vibrations thus surface quality during cutting (Das et al., 2015). In the present study, chip thickness has been measured after each run and respective CRC value is calculated and listed in Table 1. Smaller magnitude of CRC has been noticed with higher cutting speed thus at higher cutting speed lesser thickness of chip produced which indicated the lower amount of the cutting forces and vibrations during cutting. From main effects plot analysis, CRC decreases with cutting speed whereas it rises with depth of cut. Again, CRC increases when feed rises from 0.04 to $0.08 \mathrm{~mm} / \mathrm{rev}$ there after almost constant till $0.12 \mathrm{~mm} / \mathrm{rev}$ whereas it decreases when feed rises from 0.12 to $0.16 \mathrm{~mm} / \mathrm{rev}$. Also, saw tooth profile is directly related to uncut chip thickness i.e. bigger saw tooth was produced with higher uncut chip thickness. ANOVA (Similar as Table 2) and main effect plot (Fig. 5b) clearly indicated that the depth of cut and feed are significant term associated to CRC whereas cutting speed is insignificant at $95 \%$ level of confidence.

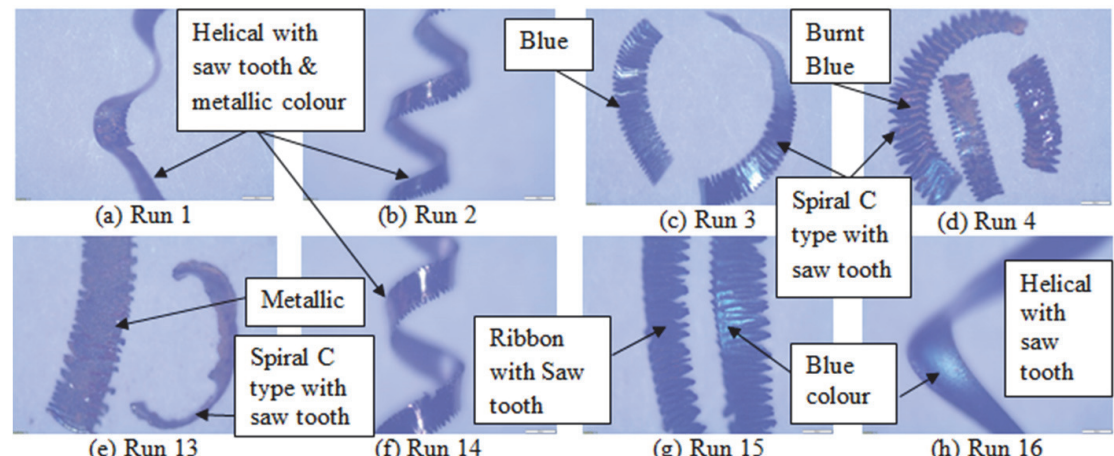

(e) Run 13

(f) Run 14

(g) Run 15

(h) Run 16

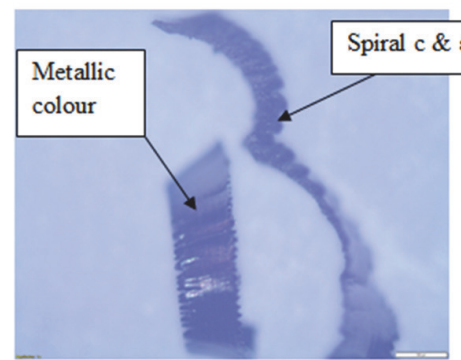

(i) Run 6

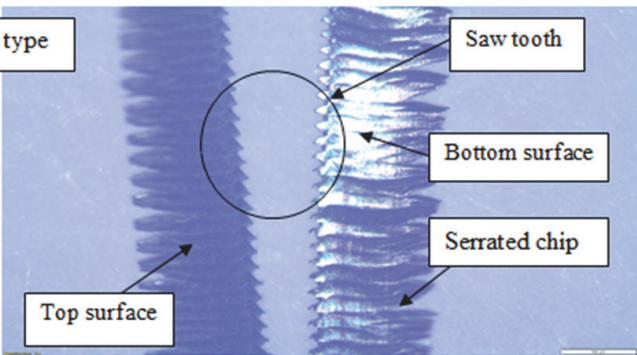

(j) Run 7

Fig. 6. Optical micrograph of chips 


\section{Design of multi response optimization}

Taguchi based grey relational analysis is implemented for optimal values of responses (Sahoo and Sahoo 2013; Mishra et al. 2015; Panda et al. 2016). In this technique first data is normalized called as grey relational generation. Second step is to find $\Delta_{\mathrm{oi}}$. Third step is to calculate grey relational coefficient where equal weightage is given to all responses. Fourth step is to calculate grey relational grade. In this way multi response is converted in to single response. Table 3 represents calculations for all the above written steps. Now further step is to calculate mean grey relational grade which is reported in Table 4. From the Table 4, larger value ensures the corresponding parameter data set is closer to the optimal result. The optimal value is identified as $d 1-f 1-v 2(d=0.1 \mathrm{~mm}, f=0.04 \mathrm{~m} / \mathrm{min}$ and $v=108 \mathrm{~m} / \mathrm{min})$. The confirmation experiment (Table 5) has been conducted between initial variable parameter setting with optimal cutting parameter setting. The predicted grey relational grade taking optimal data set of cutting variable can be calculated using the Eq. 5.

$$
\hat{\gamma}=\gamma_{m}+\sum_{i=1}^{o}\left(\bar{\gamma}_{i}-\gamma_{m}\right),
$$

where $\gamma_{m}$ represents the average of sum of all grey relational grade, $\bar{\gamma}_{i}$ represents the mean grey relational grade at the optimal level of each factor, and $o$ denotes the significant number of cutting parameters (Panda et al., 2016). The gain in GRG is noticed to be 0.474 which is greatly improved.

\section{Table 3}

Calculation of grey relational grade

\begin{tabular}{|c|c|c|c|c|c|c|c|c|c|c|c|}
\hline \multirow[t]{2}{*}{ Run No. } & \multicolumn{3}{|c|}{ Grey relational generation } & \multicolumn{3}{|c|}{$\Delta \Delta_{\mathrm{oi}}$} & \multicolumn{3}{|c|}{$\begin{array}{c}\text { Grey relational } \\
\text { coefficient }\end{array}$} & \multirow[t]{2}{*}{ GRG } & \multirow[t]{2}{*}{ Rank } \\
\hline & $\mathrm{Ra}$ & $\mathrm{T}$ & $\mathrm{VBc}$ & $\mathrm{Ra}$ & $\mathrm{T}$ & $\mathrm{VBc}$ & $\mathrm{Ra}$ & $\mathrm{T}$ & $\mathrm{VBc}$ & & \\
\hline Ideal & 1 & 1 & 1 & 1 & 1 & 1 & 1 & 1 & 1 & & \\
\hline 1 & 0.900 & 1.000 & 1.000 & 0.100 & 0.000 & 0.000 & 0.834 & 1.000 & 1.000 & 0.945 & 1 \\
\hline 2 & 0.806 & 0.926 & 0.910 & 0.194 & 0.074 & 0.090 & 0.720 & 0.871 & 0.848 & 0.813 & 2 \\
\hline 3 & 0.626 & 0.777 & 0.672 & 0.374 & 0.223 & 0.328 & 0.572 & 0.691 & 0.604 & 0.622 & 5 \\
\hline 4 & 0.171 & 0.230 & 0.313 & 0.829 & 0.770 & 0.687 & 0.376 & 0.394 & 0.421 & 0.397 & 16 \\
\hline 5 & 1.000 & 0.762 & 0.761 & 0.000 & 0.238 & 0.239 & 1.000 & 0.677 & 0.677 & 0.785 & 3 \\
\hline 6 & 0.859 & 0.601 & 0.821 & 0.141 & 0.399 & 0.179 & 0.780 & 0.556 & 0.736 & 0.691 & 4 \\
\hline 7 & 0.470 & 0.056 & 0.463 & 0.530 & 0.944 & 0.537 & 0.486 & 0.346 & 0.482 & 0.438 & 15 \\
\hline 8 & 0.230 & 0.525 & 0.582 & 0.770 & 0.475 & 0.418 & 0.394 & 0.513 & 0.545 & 0.484 & 11 \\
\hline 9 & 0.951 & 0.373 & 0.463 & 0.049 & 0.627 & 0.537 & 0.911 & 0.444 & 0.482 & 0.612 & 6 \\
\hline 10 & 0.701 & 0.000 & 0.313 & 0.299 & 1.000 & 0.687 & 0.626 & 0.333 & 0.421 & 0.460 & 13 \\
\hline 11 & 0.395 & 0.475 & 0.597 & 0.605 & 0.525 & 0.403 & 0.452 & 0.488 & 0.554 & 0.498 & 10 \\
\hline 12 & 0.180 & 0.573 & 0.672 & 0.820 & 0.427 & 0.328 & 0.379 & 0.539 & 0.604 & 0.507 & 8 \\
\hline 13 & 0.806 & 0.014 & 0.000 & 0.194 & 0.986 & 1.000 & 0.720 & 0.336 & 0.333 & 0.463 & 12 \\
\hline 14 & 0.747 & 0.174 & 0.433 & 0.253 & 0.826 & 0.567 & 0.664 & 0.377 & 0.469 & 0.503 & 9 \\
\hline 15 & 0.546 & 0.259 & 0.701 & 0.454 & 0.741 & 0.299 & 0.524 & 0.403 & 0.626 & 0.518 & 7 \\
\hline 16 & 0.000 & 0.342 & 0.597 & 1.000 & 0.658 & 0.403 & 0.333 & 0.432 & 0.554 & 0.440 & 14 \\
\hline
\end{tabular}

\section{Table 4}

Calculation of mean grey relational grade

\begin{tabular}{cccccccc}
\hline \multirow{2}{*}{ Input factors } & \multicolumn{5}{c}{ Mean grey relational grade } & \multirow{2}{*}{ Max-Min } & \multirow{2}{*}{ Rank } \\
\cline { 2 - 5 } & Level 1 & Level 2 & Level 3 & Level 4 & & 0.213 & 3 \\
$f d$ & 0.694 & 0.599 & 0.519 & 0.481 & 0.244 & 1 \\
$v$ & 0.701 & 0.617 & 0.519 & 0.457 & 0.216 & 2 \\
\hline
\end{tabular}

\section{Table 5}

Confirmation test data

\begin{tabular}{cccc}
\hline & Initial setting & Predicted setting & Optimal settings \\
\hline Level & $d 2-f 3-\nu 4$ & $d 1-f 1-v 2$ & $d 1-f 1-v 2$ \\
VBc & 0.048 & & 0.015 \\
Ra & 0.868 & & 0.44 \\
T & 177.5 & 0.905 & 108.9 \\
GRG & 0.438 & 0.474 & 0.912 \\
\hline Gain in GRG & & & \\
\hline
\end{tabular}




\section{Estimation of tool life and cost of machining}

\subsection{Tool life estimation}

Tool life has been computed on optimal set of parameters $(d=0.1 \mathrm{~mm}, f=0.04 \mathrm{~mm} / \mathrm{rev}$ and $v=108$ $\mathrm{m} / \mathrm{min}$ ). The tool life is estimated at flank wear criteria $0.3 \mathrm{~mm}$ and the tool life is found as 70 minutes as shown in Fig 7. The wear growth up to 7 min of machining is very low as shown in Fig 7. Up to 28 min of machining abrasion is noticed to be dominant mechanism for tool wear. Increasing cutting time leads to wider width of wear and formation of grooves also called notch wear started and number of grooves increases with cutting time as shown in Fig. 7. Notch wear generate due to lower toughness of ceramic tool (Kumar et al., 2003). Grzesik and Zalisz (2008) also found deep triangular shape groove on the tool tip in machining with ceramic tool. With time passes these grooves are converted in to chipping failure. However it can be said that till 56 min of machining abrasion and notch wear are predominant whereas chipping failure has been noticed at 70 min of turning. Wear width reaches to its limit $0.3 \mathrm{~mm}$ after 70 min of cutting.

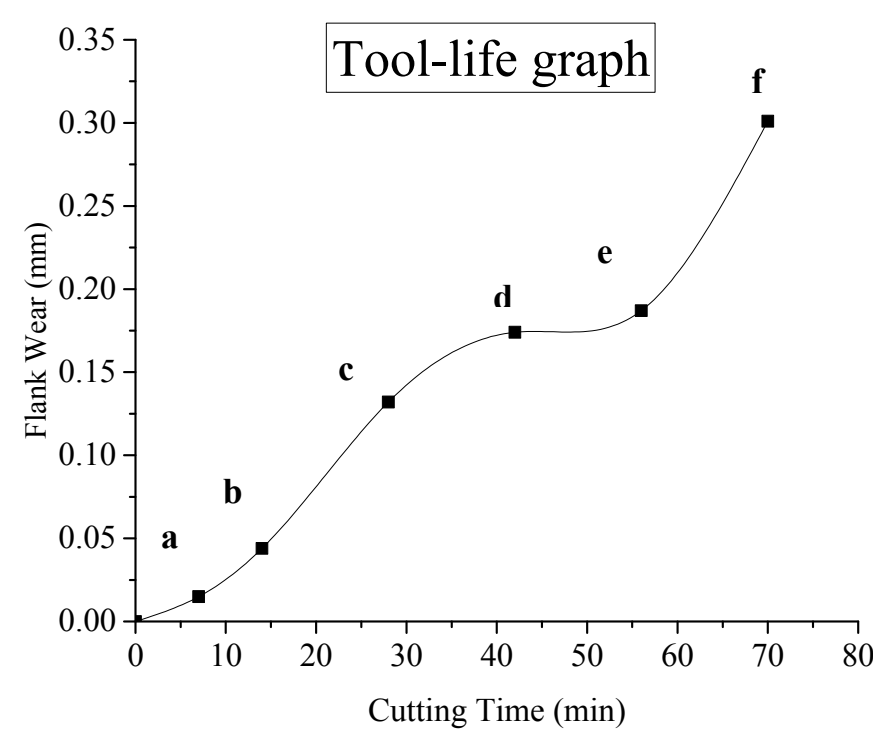

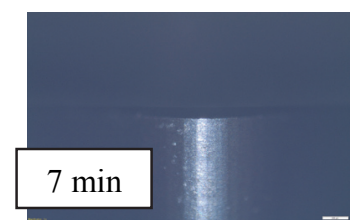

(a)

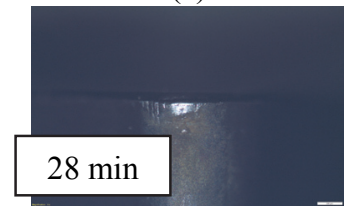

(c)

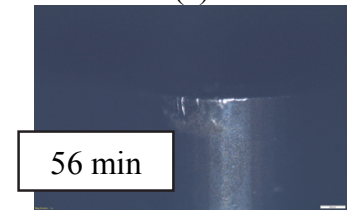

(e)

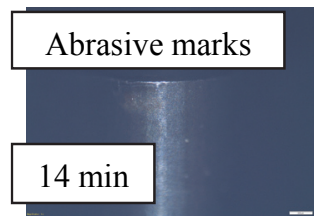

(b)

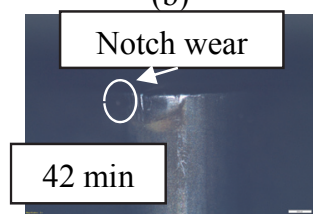

(d)

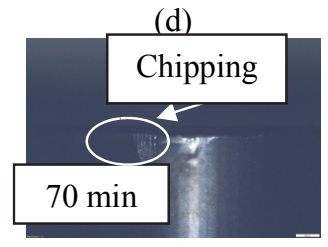

(f)

Fig. 7. Tool life estimation graph

\subsection{Cost of machining}

Gilbert's approach seemed to be very effective technique to estimate the total machining cost in turning application (More et al., 2006; Sahoo \& Sahoo, 2012). In the present study total machining cost in cylindrical turning process of AISI D2 steel $(55 \pm 1 \mathrm{HRC})$ of $100 \mathrm{~mm}$ length and $50 \mathrm{~mm}$ diameter under spray cooling condition has been carried. Cost estimation has been done using optimal value of parameters $(d=0.1 \mathrm{~mm}, f=0.04 \mathrm{~mm} / \mathrm{rev}, v=108 \mathrm{~m} / \mathrm{min})$ and tool life $\left(\mathrm{T}_{1}\right)$ of insert at flank wear criteria $0.3 \mathrm{~mm}$ is found to be 70 minutes. Idle time $\left(\mathrm{T}_{\mathrm{i}}\right) 5$ minutes has been taken in the present work. The total cost combine with machine tool, coolant and operator $(\mathrm{m})$ is taken as Rs1000 per hour $\left(16.67 \mathrm{~min}^{-1}\right)$. The commercial rate of ceramic tool is Rs 904 per insert and each insert consist of 4 useful cutting edges. Hence, the average cost per cutting edge (n) is calculated to be Rs 226. The following steps have been implemented for economic analysis.

Step 1 Machining time in one complete run $\left(\mathrm{T}_{\mathrm{m}}\right)=\frac{\pi D L}{1000 v}=3.64 \mathrm{~min}$

Step 2 Machining cost in one complete run $=\left(\mathrm{m} \cdot \mathrm{T}_{\mathrm{m}}\right)=\mathrm{Rs} 60.68$

Step 3 Tool replacing cost $=\left[\mathrm{m} \mathrm{T}_{\mathrm{i}}\left(\mathrm{T}_{\mathrm{m}} / \mathrm{T}_{1}\right)\right]=\mathrm{Rs} 4.33$ 
Step 4 Cutting tool cost per cut $=\left[\mathrm{n}\left(\mathrm{T}_{\mathrm{m}} / \mathrm{T}_{\mathrm{l}}\right)\right]=$ Rs 11.75

Step 5 Total machining cost per cut $(\mathrm{C})=$ Sum of cost estimated in steps 2,3 and $4=$ Rs 76.76

\section{Conclusions}

This paper investigated the application of environmental friendly accelerated spray cooling in hard turning of AISI D2 steel using mixed ceramic cutting tool and studied the machinability aspects. The developed empirical models have higher determination coefficients $\left(\mathrm{R}^{2}\right)$ presenting significance of model as it approaches to unity. Measured flank wear for each run lies within the recommended range of 0.3 $\mathrm{mm}$ and even below $0.1 \mathrm{~mm}$ under spray cooling condition without the consequence of any brittle fracture. Abrasion is main tool wear mechanism noticed and due to abrasive behavior of hard elements associated with D2 steel and it matches with the previous researchers (Pavel et al., 2005 and Das et al., 2015). Chipping has been noticed at highest cutting speed and depth of cut with lowest feed (Yallese et al., 2004). ANOVA result has shown that cutting speed is the highest significant parameter for flank wear succeeded by depth of cut whereas feed is traced to be insignificant. Measured surface roughness for all experiment lies within the recommended limit of 1.6 microns. Till $0.08 \mathrm{~mm} / \mathrm{rev}$, feed with entire range of cutting speed and depth of cut, surface roughness is recorded to be below 0.7 micron and comparable with cylindrical grinding. Surface roughness increases with rise of feed and identified as significant term whereas speed and depth of cut are not statically important. The cutting temperature at chip-tool junction varies from $101^{\circ} \mathrm{C}$ to $182^{\circ} \mathrm{C}$ which is lower in range and shows the capability of spray cooling system for diminishing the friction that leads to reduction of the temperature and consequently reduces the heat at the cutting zone. Cutting speed and depth cut are significant factors for cutting temperature. In spraying process, some portion of spraying coolant vaporize due to heat when it reaches to cutting zone whereas remaining portion of coolant easily penetrate in cutting zone through capillary action and reduces friction as well as heat in cutting zone. Helical, spiral c type, spiral $\mathrm{c}$ and $\varepsilon$ type and ribbon shaped chips have been produced. Saw tooth pattern on chips have been noticed because of periodic fracture by generating very high concentrating shear bands (Das et al., 2015). Upper portion of the chip is plastically deformed and looks very dull whereas the bottom surface of chip is smooth and shiny. This is because of continuous rubbing between tool and chip surface. Serrated chips have been identified at higher cutting speed and higher feeds. Depth of cut and feed are significant terms associated to CRC whereas cutting speed is insignificant. The optimal parametric value is identified as $d 1-f 1-v 2(0.1 \mathrm{~mm}-0.04 \mathrm{~m} / \mathrm{min}-108 \mathrm{~m} / \mathrm{min})$ and the gain in grey relational grade is noticed as 0.474 . Tool life is estimated at optimal parameters and found to be 70 minutes which is significantly higher under ACE environment. Abrasive marks, grooves (notch wear) and chipping of tool tip are noticed with progress of cutting time. Total machining cost per part is estimated as Rs 76.76. From experimental investigations, it concludes that hard turning of AISI D2 steel under ACE environment leads to higher machinability. Tool life is greatly improved and cost of machining per part is quite less. Flank wear and surface roughness values are well within the criteria limit without any brittle fracture of cutting inserts under ACE. It shows the worthy of application of ACE in hard turning environment with ceramic insert ecologically and economically in industrial sectors.

\section{Acknowledgements}

The authors express their gratitude and thank to KIIT University for providing the experimental facility to execute the research work.

\section{References}

Aslantas, K., Ucun, I., \& Cicek, A. (2012). Tool life and wear mechanism of coated and uncoated Al 2 O 3/TiCN mixed ceramic tools in turning hardened alloy steel. Wear, 274, 442-451.

Basak, S., Dixit, U. S., \& Davim, J. P. (2007). Application of radial basis function neural networks in optimization of hard turning of AISI D2 cold-worked tool steel with a ceramic tool. Proceedings of 
the Institution of Mechanical Engineers, Part B: Journal of Engineering Manufacture, 221(6), 987998.

Chinchanikar, S., \& Choudhury, S. K. (2014). Evaluation of chip-tool interface temperature: effect of tool coating and cutting parameters during turning hardened AISI 4340 steel. Procedia Materials Science, 6, 996-1005.

Chinchanikar, S., \& Choudhury, S. K. (2015). Machining of hardened steel-experimental investigations, performance modeling and cooling techniques: a review. International Journal of Machine Tools and Manufacture, 89, 95-109.

Das, S. R., Dhupal, D., \& Kumar, A. (2015). Experimental investigation into machinability of hardened AISI 4140 steel using TiN coated ceramic tool. Measurement, 62, 108-126.

Davim, J. P., \& Figueira, L. (2007). Machinability evaluation in hard turning of cold work tool steel (D2) with ceramic tools using statistical techniques. Materials \& design, 28(4), 1186-1191.

De Godoy, V. A. A., \& Diniz, A. E. (2011). Turning of interrupted and continuous hardened steel surfaces using ceramic and CBN cutting tools. Journal of Materials processing technology, 211(6), 10141025.

Ferreira, R., Carou, D., Lauro, C. H., \& Davim, J. P. (2016). Surface roughness investigation in the hard turning of steel using ceramic tools. Materials and Manufacturing Processes, 31(5), 648-652.

Gaitonde, V. N., Karnik, S. R., Figueira, L., \& Davim, J. P. (2009). Machinability investigations in hard turning of AISI D2 cold work tool steel with conventional and wiper ceramic inserts. International Journal of Refractory Metals and Hard Materials, 27(4), 754-763.

Grzesik, W. (2008). Influence of tool wear on surface roughness in hard turning using differently shaped ceramic tools. Wear, 265(3), 327-335.

Grzesik, W., \& Zalisz, Z. (2008). Wear phenomenon in the hard steel machining using ceramic tools. Tribology International, 41(8), 802-812.

Grzesik, W. (2009). Wear development on wiper Al 2 O 3-TiC mixed ceramic tools in hard machining of high strength steel. Wear, 266(9), 1021-1028.

Gupta, A. K. (2010). Predictive modelling of turning operations using response surface methodology, artificial neural networks and support vector regression. International Journal of Production Research, 48(3), 763-778.

Kumar, A. S., Durai, A. R., \& Sornakumar, T. (2003). Machinability of hardened steel using alumina based ceramic cutting tools. International Journal of Refractory Metals and Hard Materials, 21(3), 109-117.

Liu, J., Han, R., \& Sun, Y. (2005). Research on experiments and action mechanism with water vapor as coolant and lubricant in Green cutting. International Journal of Machine Tools and Manufacture, 45(6), 687-694.

Makadia, A. J., \& Nanavati, J. I. (2013). Optimisation of machining parameters for turning operations based on response surface methodology. Measurement, 46(4), 1521-1529.

Mandal, N., Doloi, B., Mondal, B., \& Das, R. (2011). Optimization of flank wear using Zirconia Toughened Alumina (ZTA) cutting tool: Taguchi method and Regression analysis. Measurement, 44(10), 2149-2155.

Mia, M., \& Dhar, N. R. (2016). Prediction of surface roughness in hard turning under high pressure coolant using Artificial Neural Network. Measurement, 92, 464-474.

Mir, M., \& Wani, M. (2018). Modelling and analysis of tool wear and surface roughness in hard turning of AISI D2 steel using response surface methodology. International Journal of Industrial Engineering Computations, 9(1), 63-74.

Mishra, P., Das, D., Ukamanal, M., Routara, B., \& Sahoo, A. (2015). Multi-response optimization of process parameters using Taguchi method and grey relational analysis during turning AA 7075/SiC composite in dry and spray cooling environments. International Journal of Industrial Engineering Computations, 6(4), 445-456.

More, A. S., Jiang, W., Brown, W. D., \& Malshe, A. P. (2006). Tool wear and machining performance of cBN-TiN coated carbide inserts and PCBN compact inserts in turning AISI 4340 hardened steel. Journal of Materials Processing Technology, 180(1), 253-262. 
Özel, T., Karpat, Y., Figueira, L., \& Davim, J. P. (2007). Modelling of surface finish and tool flank wear in turning of AISI D2 steel with ceramic wiper inserts. Journal of materials processing technology, 189(1), 192-198.

Pal, A., Choudhury, S. K., \& Chinchanikar, S. (2014). Machinability assessment through experimental investigation during hard and soft turning of hardened steel. Procedia Materials Science, 6, 80-91.

Panda, A., Sahoo, A., \& Rout, R. (2016). Multi-attribute decision making parametric optimization and modeling in hard turning using ceramic insert through grey relational analysis: A case study. Decision Science Letters, 5(4), 581-592.

Pavel, R., Marinescu, I., Deis, M., \& Pillar, J. (2005). Effect of tool wear on surface finish for a case of continuous and interrupted hard turning. Journal of Materials Processing Technology, 170(1), 341349.

Quiza, R., Figueira, L., \& Davim, J. P. (2008). Comparing statistical models and artificial neural networks on predicting the tool wear in hard machining D2 AISI steel. The International Journal of Advanced Manufacturing Technology, 37(7-8), 641-648.

Rout, A., Satapathy, A., Mantry, S., Sahoo, A., \& Mohanty, T. (2012). Erosion wear performance analysis of polyester-gf-granite hybrid composites using the Taguchi method. Procedia Engineering, 38, 1863-1882.

Sahin, Y. (2009). Comparison of tool life between ceramic and cubic boron nitride (CBN) cutting tools when machining hardened steels. Journal of materials processing technology, 209(7), 3478-3489.

Sahoo, P., Barman, T. K., \& Routara, B. C. (2008). Fractal dimension modelling of surface profile and optimisation in $\mathrm{CNC}$ end milling using response surface method. International Journal of Manufacturing Research, 3(3), 360-377.

Sahoo, A. K., \& Sahoo, B. (2012). Experimental investigations on machinability aspects in finish hard turning of AISI 4340 steel using uncoated and multilayer coated carbide inserts. Measurement, 45(8), 2153-2165.

Sahoo, A. K., \& Sahoo, B. (2013). Performance studies of multilayer hard surface coatings (TiN/TiCN/ $/{ }_{2} \mathrm{O}_{3} / \mathrm{TiN}$ ) of indexable carbide inserts in hard machining: Part-I (An experimental approach). Measurement, 46(8), 2854-2867.

Sahoo, A. K., \& Sahoo, B. (2013). Performance studies of multilayer hard surface coatings (TiN/TiCN/ $/ \mathrm{Al}_{2} \mathrm{O}_{3} / \mathrm{TiN}$ ) of indexable carbide inserts in hard machining: Part-II (RSM, grey relational and techno economical approach). Measurement, 46(8), 2868-2884.

Sahu, S. K., Mishra, P. C., Orra, K., \& Sahoo, A. K. (2015). Performance assessment in hard turning of AISI 1015 steel under spray impingement cooling and dry environment. Proceedings of the Institution of Mechanical Engineers, Part B: Journal of Engineering Manufacture, 229(2), 251-265.

Shalaby, M. A., El Hakim, M. A., Abdelhameed, M. M., Krzanowski, J. E., Veldhuis, S. C., \& Dosbaeva, G. K. (2014). Wear mechanisms of several cutting tool materials in hard turning of high carbonchromium tool steel. Tribology International, 70, 148-154.

Sharma, J., \& Sidhu, B. S. (2014). Investigation of effects of dry and near dry machining on AISI D2 steel using vegetable oil. Journal of Cleaner Production, 66, 619-623.

Neşeli, S., Yaldız, S., \& Türkeş, E. (2011). Optimization of tool geometry parameters for turning operations based on the response surface methodology. Measurement, 44(3), 580-587.

Yallese, M. A., Rigal, J. F., Chaoui, K., \& Boulanouar, L. (2005). The effects of cutting conditions on mixed ceramic and cubic boron nitride tool wear and on surface roughness during machining of X200Cr12 steel (60 HRC). Proceedings of the Institution of Mechanical Engineers, Part B: Journal of Engineering Manufacture, 219(1), 35-55.

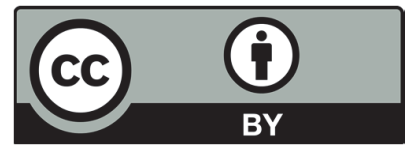

(C) 2018 by the authors; licensee Growing Science, Canada. This is an open access article distributed under the terms and conditions of the Creative Commons Attribution (CCBY) license (http://creativecommons.org/licenses/by/4.0/). 